\title{
Jahrestagung 2001
}

Vom 3. bis 6. Oktober 2001 hielt die Vereinigung der Deutschen Staatsrechtslehrer ihre Jahrestagung in Würzburg ab, wo sie bereits einmal im Jahre 1965 getagt hat. Zu Beginn der Mitgliederversammlung gedachte die Vereinigung ihrer verstorbenen Mitglieder Erwin Melichar und Ignaz Seidl-Hohenveldern. Der Vorsitzende konnte in der Mitgliederversammlung 32 neue Mitglieder begrüßen, die sich kurz vorstellten. Die Vereinigung zählt jetzt 520 Mitglieder.

Der Tag der Deutschen Einheit wurde mit einem Orgelkonzert in der Alten Universität und einem Empfang des Präsidenten der Universität Würzburg und des Oberbürgermeisters der Stadt Würzburg beschlossen. Zu Mitgliedern des Vorstandes für die Jahre 2002 und 2003 wurden gewählt: Gunnar Folke Schuppert, Beatrice Weber-Dürler und Helmuth SchulzeFielitz.

Nach Begrüßung durch den Dekan der Juristischen Fakultät, Professor Dr. Horst Dreier, wurde am Donnerstag der erste Beratungsgegenstand „Verfassungsrecht und einfaches Recht - Verfassungsgerichtsbarkeit und Fachgerichtsbarkeit" behandelt. Es referierten Robert Alexy, Kiel, Philip Kunig, Berlin, Werner Heun, Göttingen, und Georg Hermes, Frankfurt' Main. Die Aussprache stand unter der Leitung von Jörn Ipsen. Am Freitag wurde der zweite Beratungsgegenstand „Primär- und Sekundärrechtsschutz im öffentlichen Recht" behandelt. Es referierten Wilfried Erbguth, Rostock, Wolfram Höfling, Köln, Rudolf Streinz, Bayreuth, und Astrid Epiney, Freiburg (Schweiz). Die Aussprache stand unter der Leitung von Hartmut Bauer. Der Freitag wurde mit einem geselligen Abend im Weindom unter der Fürstbischöflichen Residenz mit Weinprobe, Winzerschmaus und einer "Weinrede" von Udo Steiner beendet.

Der Ausflug am Samstag führte in die Lande um den Main. Die Mitglieder wurden von der Landrätin des Kreises Kitzingen sowie von dem Bürgermeister von Volkach jeweils zusammen mit Weinprinzessinnen und einem Stadtrat empfangen. Vorzüglicher fränkischer Wein wurde überall ausgeschenkt. Ganz besonderer Dank für die Vorbereitung der Tagung gilt Franz-Ludwig Knemeyer sowie für die Organisation des Begleitprogramms Frau Knemeyer. Die alte Fürstbischöfliche Residenz am Main hat der Tagung einen besonderen Rahmen gegeben. 
